\title{
Exploration and practice of the cultivation of optoelectronic innovative talents based on the Students Innovation Training Program
}

Bing Lei, Wei Liu, Jianhua Shi, Tianfu Yao, Wei Wang, et al.

Bing Lei, Wei Liu, Jianhua Shi, Tianfu Yao, Wei Wang, Haojun Hu, "Exploration and practice of the cultivation of optoelectronic innovative talents based on the Students Innovation Training Program," Proc. SPIE 10452, 14th Conference on Education and Training in Optics and Photonics: ETOP 2017, 1045242 (16 August 2017); doi: 10.1117/12.2266457

Event: 14th Conference on Education and Training in Optics and Photonics, ETOP 2017, 2017, Hangzhou, China 


\title{
Exploration and practice of the cultivation of optoelectronic innovative talents based on the Students Innovation Training Program
}

\author{
Bing Lei*, Wei Liu, Jianhua Shi, Tianfu Yao, Wei Wang and Haojun Hu \\ College of Optoelectronic Science and Engineering, National University of Defense Technology, \\ Changsha, Hunan 410073, China
}

\begin{abstract}
The Students Innovation Training Program (SITP) has become an effective method to impel the teaching reform and improve undergraduate's innovative practical ability in Chinese colleges and universities, which is quite helpful for students to understand the social requirement, to grasp the basic means of scientific research and to improve their innovative practical ability and team work spirit.

In this paper, three problems have been analyzed and discussed based on our organizing and instructing experience of SITP in recent years. Firstly, the SITP is a synthetically training project, and it is quite suitable to cultivate the students' innovative practical ability. Because SITP is similar to the real scientific research activity, and both of them include the steps of project application, solution design, research implementation and project summary etc. By making great efforts to these basic training steps, the undergraduates' innovative practical ability has been improved systemically. Secondly, a new talents cultivation system has been constructed based on SITP by integrating the subject competitions, graduation design and other conventional training activities, which is quite good to improve the training quality and decrease the total training class hours. Thirdly, a series of long-term effective operation and management guidelines have been established to ensure the SITP work normally, including doing a good job of project evaluation, setting up a reward and punishment system and creating a good atmosphere for innovation.
\end{abstract}

In conclusion, great efforts have been made to enhance undergraduates' innovative ability, and the research results will provide useful reference for improving the training effects and reforming talents cultivating mode further.

Keywords: Students Innovation Training Program, innovative and practical education, cultivation of optoelectronic innovative talents, innovative practical ability, research learning

\section{INTRODUCTION}

In order to reform talents cultivation mode and train undergraduates' innovation practical ability, the Students Innovation Training Program (SITP) is set up by the Chinese Ministry of Education in 2012, which is the key construction project of 'the Undergraduate Teaching Quality and Teaching Reform'. The SITP is a series of comprehensive training activities, which includes the basic steps of building a researching team, actualizing the research learning independently, carrying out project application, solution design, experimental data analysis and processing, writing research reports and papers, and summarizing project under the guidance of teacher. As we all known, the SITP has been widely implemented and extensive influence has been produced in domestic colleges and universities. According to the statistical data of Chinese Ministry of Education, the numbers of national level SITP have been approved are 25262, 19741, 21716, 24864 and 27375 from year 2012 to 2016 respectively, and hundreds of colleges and universities have participated in the program actively [1].

In this paper, exploring the new cultivation mode of optoelectronic innovative talents based on SITP, how to construct new talents cultivation system and improve the undergraduates' innovative practical ability systemically, how to improve the training quality and decrease the total training class hours, and how to establish the long-term effective operation and management guidelines to ensure the SITP work normally, have been researched and discussed in detail.

*leibing_2000@126.com; phone 086 0731-84574749

14th Conference on Education and Training in Optics and Photonics: ETOP 2017, edited by Xu Liu,

Xi-Cheng Zhang, Proc. of SPIE Vol. 10452, 1045242 · ( 2017 ICO, IEEE, OSA, SPIE

CCC code: $0277-786 X / 17 / \$ 18 \cdot$ doi: $10.1117 / 12.2266457$ 


\section{IMPROVING INNOVATIVE PRACTICAL ABILITY BASED ON SITP}

The SITP is a synthetically training program and it is quite suitable to train undergraduates' innovative practical ability, which is also the most similar to the real scientific research activity. Since both the SITP and scientific research activity include the basic steps of selecting the research topic, literature investigation and reading, project application, solution design and provement, theory analysis and simulation, experimental validation, making a demonstration system, writing a scientific research report, summarizing the research achievements and findings, and academic exchange etc., the SITP can make students experience the whole process of a real scientific research project. Furthermore, the research period of SITP is usually from one to three years, and the support funds can reach 20 thousand yuan. By paying main attention to and making great efforts to these basic training steps, the undergraduates' innovative practical ability can be improved systemically. The basic main steps for training the undergraduates' innovative practical ability based on SITP have been summarized and shown in Fig. 1.

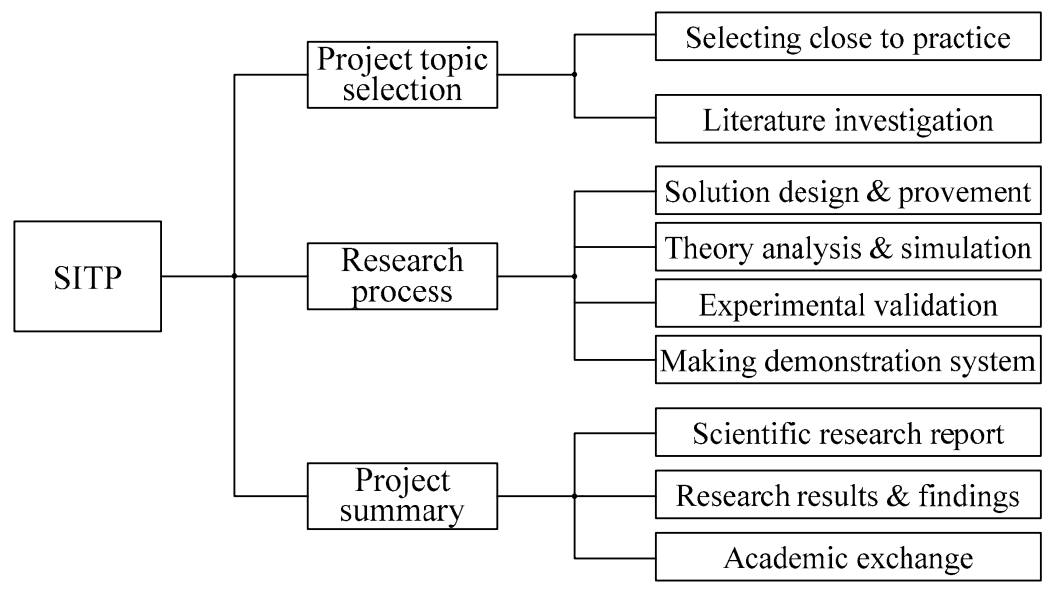

Fig. 1 Basic steps for training the undergraduates' innovative practical ability based on SITP.

According to our organizing and instructing experience of SITP in recent years, we have found that the three steps of selecting the research topic, carrying out the research process and project summary are the most important things need to be made great efforts to [1]. Firstly, the selection of SITP project should be based on the students' interest and major, and the creativity, exploration, difficulty and feasibility are the important factors need to be considered. The research topic of SITP project should also be close to practice and it can be from the students' study and life experience, and it can also be from the instructor's teaching and researching work, as long as the selected research topic has some problems owning theoretical and practical significance needed to be solved. Moreover, the convenience of conversion from SITP to subject competitions, graduation design and other conventional training activities, is another key factor need to be considered when choose a appropriate SITP research subject. The typical topics of our university selected in recent years are shown in Tab. 1.

Tab. 1 The typical topics of our university selected in recent years

\begin{tabular}{c|c|c}
\hline Year & Name of the selected topic of SITP & Grant number \\
\hline 2012 & The high precision velocimeter of multiple vehicles based on image recognition & 201290002064 \\
\hline 2012 & Development of the intelligent hearing protection system & 201290002069 \\
\hline 2013 & Study on the anti-disclosure screen based on polarization techniques & 201390002057 \\
\hline 2013 & A novel contactless input system based on infrared reflecting detection array & 201390002060 \\
\hline 2014 & Rapid detection method of hogwash oil based on optoelectric detection technology & 201490002063 \\
\hline 2014 & Development of the intelligent muscles vibration and relaxation system & 201490002100 \\
\hline 2015 & Experimental study on coherent combining of multi-wavelength fiber lasers & 201590002068 \\
\hline 2016 & Design and realization of a simple laser communication system & 201690002050 \\
\hline
\end{tabular}


Secondly, strengthening the guide and carrying out research process is the most important step of SITP, which is the key step to enlighten and train undergraduates' innovative practical ability. The research process of SITP contain the basic aspects of solution design and comparison, theory analysis and simulation, experimental validation and making demonstration system, which are helpful to train the students' comprehensive ability. Although SITP and real scientific project have the same research procedure, less attention should be paid to the detailed results and targets in SITP. In other words, we should pay more attention to grasping the research method, attempting their strange ideas and specific performance in implementing the research process, rather than worried about whether the students can finish the research task or not; as long as a large number of detailed research work have been done and explicit results have been achieved, the students' work should be approved in the evaluation process.

Thirdly, summarizing the research achievements and publishing related papers are another important part to train the undergraduates' scientific writing and explaining ability. If some achievements or significant results have been obtained, we should encourage the students to summarize their research work timely, writing the technical reports and papers and applying the patents. The submitted reports should contain detailed experimental data, research method and process, and the particular results. The PowerPoint presentation is also needed in routine inspection, which requires students to state their main research work and answer the experts' inquiry. Moreover, recommending good SITP projects to present and exhibit in academic conference or various work show is also a good way to communicate with other professional persons and improve the SITP projects.

\section{CONSTRUCTING A TALENTS CULTIVATION SYSTEM BASED ON SITP}

In order to improve the training quality and decrease the total training class hours, the new talents cultivation system has been constructed based on SITP by integrating the subject competitions, graduation design and other conventional training activities, which is shown in Fig. 2. As we all known, SITP is a synthetically training project which is set up for improving undergraduates' innovative practice and scientific research ability, and its typical properties are wide research field, long training period, large support funds and developing versatile ability. Three basic principles of carrying out SITP are independent research, interest driven and focus on process. Both the typical properties and implementing principles of SITP indicate its crucial place and function in cultivating undergraduates' innovative practice ability, and it is quite appropriate to excite students' interest and creativity.

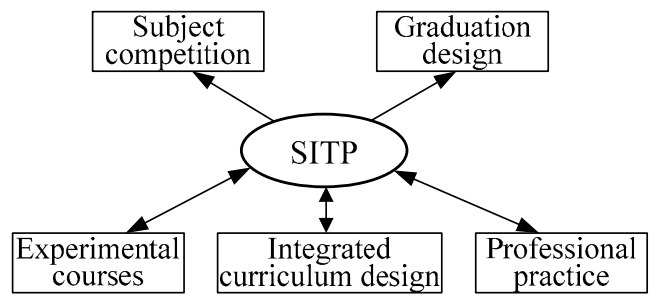

Fig. 2 The constructed new talents cultivation system based on SITP.

The operation process of the new talents cultivation system is designed to work like this. At first, the basic practical skill is studied and trained by conventional teaching activities, such as experimental courses, integrated curriculum design, professional practice etc., and these basic practical skills will provide students a quite good foundation to implement the SITP project. Then the scientific research skills, such as literature retrieving and reading, solution design and provement, theory analysis and simulation, making a demonstration system, summarizing the research achievements and findings, writing the summary reports and scientific papers, academic exchange, team cooperation and organization, can be trained well by SITP. Finally, these well trained students can take part in various subject competitions on the basis of SITP, and the graduation design task can also be accomplished by expanding and deepening the research work of SITP further. What is more, the SITP project passed through the expert evaluation can be utilized to offset the project owners' credit hours in practical optional course. All of the above measures can improve the training effect with less total training class hours, and the quality of completing the subject competitions and graduation design can become better than before.

To construct the new innovative practical ability cultivating system, it is not only necessary to play an important role of SITP in various training activities, but also needed to form the new teaching concept and talents cultivating mode. A new innovative talents cultivating mode, which is called 'learning in practice, research in learning, creating in research', has been summarized and proposed $[2,3]$. Under the guidance of new teaching concept and talents cultivating mode, the 
students have to learn voluntarily with the questions needed to be solved, and the training process become from 'asked to learn' to 'we want to learn', therefore the training effect is much better than usual teaching way.

We have instructed several dozen of SITP projects in recent years and the above mentioned teaching reform measures have been adopted in practice, and good teaching results have been achieved. Taking two finished national level SITPs 'Development of the intelligent hearing protection system (201290002069)' and 'A novel contactless input system based on infrared reflecting detection array (201390002060)' as example, both of them have obtained the 'A' grade (less than 10 percent) in the quality assessment of our university. Based on the research results and findings of these two projects, two national invention patents have been applied and approved, one scientific paper indexed by EI (engineering index) has been published, and six awards have been obtained in subject competitions. It is worth mentioning that the former work 'intelligent hearing protection system' had won the first prize in 2013 international contest of applications in NanoMicro technology (iCAN'13), and the award certificate and object picture are presented in Fig. 3.
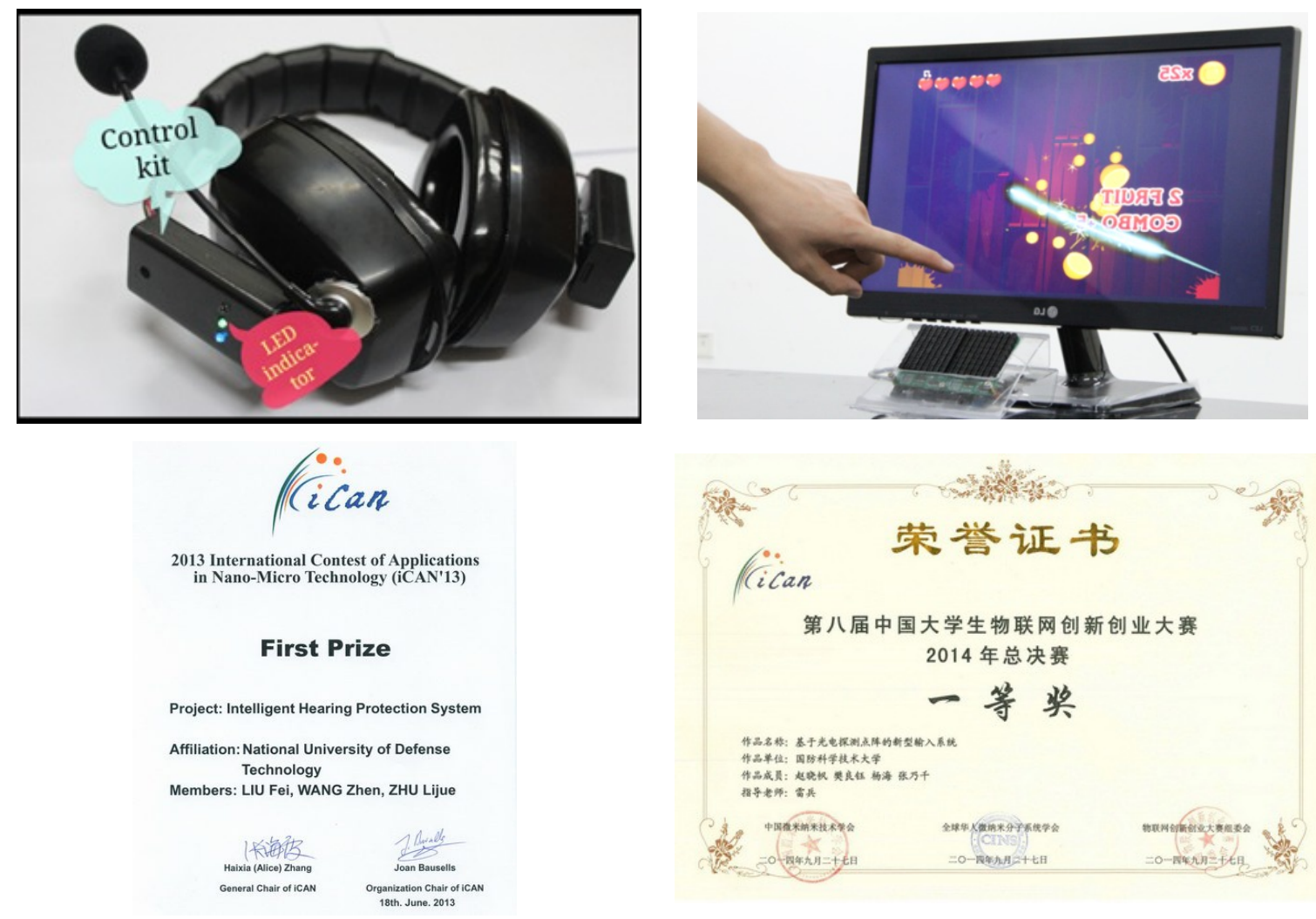

Fig. 3 The award certificate and object picture of two typical SITP works.

\section{ESTABLISHING OPERATION AND MANAGEMENT GUIDELINES OF SITP}

In order to ensure the SITP work normally and develop sustainably, it is necessary to establish a series of long-term effective operation and management guidelines [4-7]. In May 2012, the implementing management measures of students innovation training program have been established and issued by National University of Defense Technology (NUDT), which provide a detailed explanation about the SITP's significance, implementing principle, project application and evaluation, organization and management, funding spending etc. Three important tasks, including doing a good job of project evaluation, setting up a reward and punishment system with guiding quality and creating a good atmosphere for innovation, are needed to be made great efforts to implement.

The SITP project evaluation contains three different reviewing steps, which are approval evaluation, middle-term review, and final assessment. Three-review procedures are quite important to ensure the accomplishing quality of SITP, which 
can be implemented by multiple ways, such as internet review, live argument and debate in meeting room, and real work show. Three-review procedures can not only supervise and speed up the fulfillment of research tasks, but also provide the students some good suggestions and help them to solve the difficult problems in their research practice. Furthermore, Three-review procedures are also good opportunity to summarize the research achievements, which include explicit and implicit achievements. The former contains scientific research paper, national invention patents, and subject competition awards, and the latter contains improving the project owners' scientific research ability and innovative practical ability.

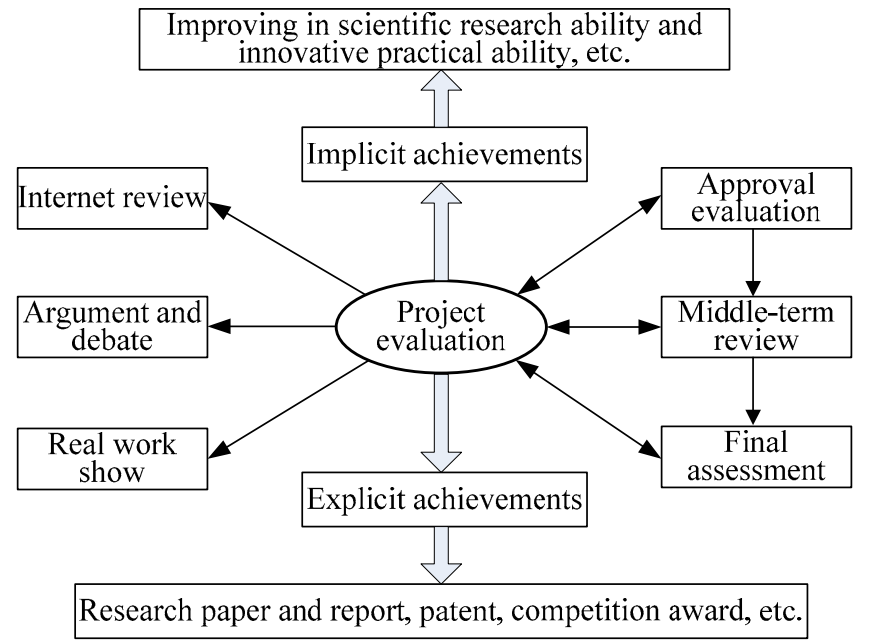

Fig. 4 The three-review procedures and main achievements of SITP.

Setting up a reward and punishment system with guiding quality is another important job needed to be done well. Most of the SITP projects can accomplish their research work timely, but there still exist a small part of projects finishing their work with poor quality. To supervise the students, instructors and the grass-root managing unit to make great efforts to fulfill the SITP work, some reward and punishment measures are really necessary. If the project has accomplished and obtained the 'A' grade, the students can get the credit hours of practical optional course and have the priority to be rated as excellent graduated students and to be recommended as postgraduates. On the other hand, if the project does not pass the final assessment, the project owners and their instructor should be punished.

The last important thing is to create a positive innovation atmosphere for SITP, which can be realized by holding topic lectures, innovative salons, discussion and debate meetings and taking part in various academic activities based on the introduction of excellent SITP projects. The innovation forum and science technology and culture festival are also good platform for showing the SITP works, communicating academic thoughts, and inspiring ideas to solve problems. What is more, organizing the excellent SITP project owners to join academic conferences and related communication activities is also beneficial for creating a good innovation atmosphere. Fig. 5 are the live pictures of undergraduates joining academic communication activities.
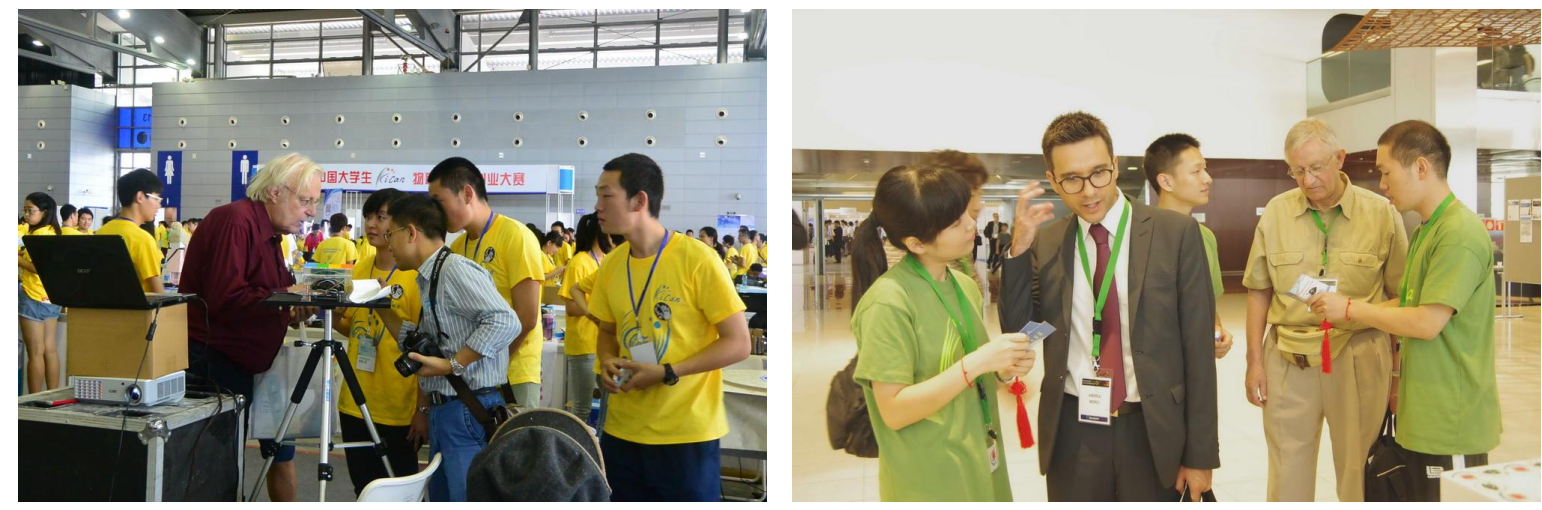

Fig. 5 The live pictures of undergraduates joining academic communication activities. 


\section{CONCLUSION}

SITP is an effective approach to impel the teaching reform and cultivating undergraduate's innovative practical ability in Chinese universities, which is quite helpful for students to grasp the basic means of scientific research and to improve their innovative practical ability. According to the practical experience of organizing and instructing the SITP projects in recent years, the new cultivation mode of optoelectronic innovative talents has been explored and practiced based on SITP. Three problems have been analyzed and discussed in this paper, which are training students' innovation practical ability integrally, forming the talents cultivation structure based on SITP and constructing long-term effective operation and management mechanism. The research results provide helpful reference for improving the SITP's training effects and reforming talents cultivation mode further.

\section{Acknowledgments}

This work is supported by the education and teaching research undergraduate project of National University of Defense Technology (Grant No. U2016007) and the education and teaching reform research project of College of Optoelectronic Science and Engineering, National University of Defense Technology (Grant No. 2015XY03).

\section{REFERENCES}

[1] B. Lei, Y. Feng, W. Liu, J. H. Shi, H. J. Hu, "Exploration on cultivating mode of talents with innovation practical ability based on SITP," Research in Teaching 38(6), 97-101 (2015).

[2] J. M. Zheng, "Constructing an innovative practice platform combining with "doing, learning and studying,", Experimental Technology and Management 27(1), 1-4 (2010).

[3] C. H. Liu, X. H. Li, G. Li, Q. R. Yue, Y. G. Ren, "Practice and exploration of the undergraduate innovation and entrepreneurship training program," Research and Exploration in Laboratory 33(5), 163-166 (2014).

[4] L. M. Li, G. Y. He, Z. J. Liu, Y. J. Li, H. X. Liu, "The students innovation training program and cultivation of innovative talents," Higher Education of Sciences 79(3), 84-86 (2008).

[5] L. Guo, H. Wang, X. N. Wang, "Researching for the management of 'innovation and entrepreneurship training project for college students'," Modern Education Technology 22(6), 118-121 (2012).

[6] X. Geng, "Practice and exploration of the undergraduate innovation and entrepreneurship training program," Contemporary Economics 8, 88-89 (2014).

[7] L. G. Chen, "Cultivation of innovation ability of Chemistry major students based on college students' innovation training project," Higher Education Forum 3(3), 27-29 (2013). 